\title{
Antioxidant and cytotoxic activities of alkaloids extracted from inermis nopals of Algerian Opuntia ficus-indica ( $L$ ).
}

\author{
Badreddine Moussaoui ${ }^{1}$, Abdellah Rahali1 ${ }^{1}$ Djahira Hamed ${ }^{1}$, Laid Guemou², Ali Riazi ${ }^{*}$ \\ ${ }^{1}$ Laboratory of Beneficial Microorganisms, Functional Food and Health (LMBAFS), Faculty of Natural and Life Sciences, \\ Abdelhamid Ibn Badis University, Mostaganem, Algeria \\ ${ }^{2}$ Laboratory of Improvement and Promotion of Local Animal Productions (LAVPAL), Faculty of Natural Sciences and \\ Life, University of Ibn Khaldoun, Tiaret, Algeria
}

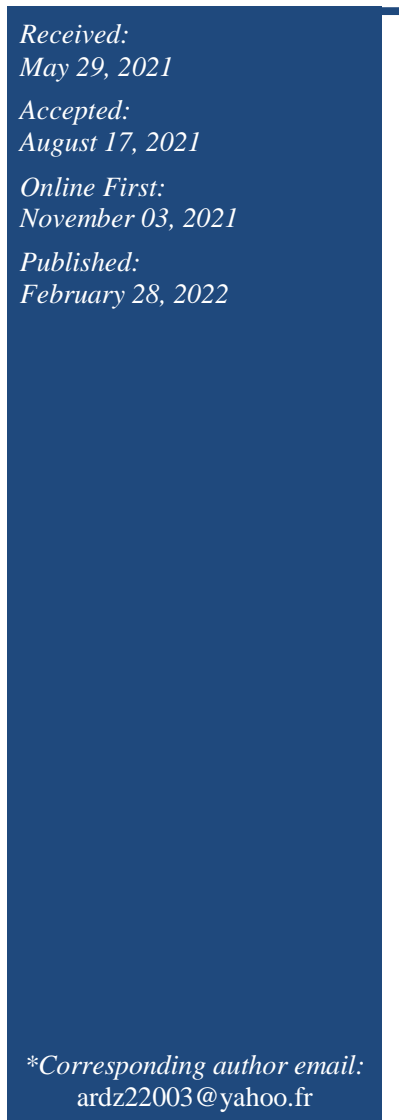

\begin{abstract}
The prickly pear (Opuntia ficus-indica L.) is not only prized for its fruit but also for its cladode which contains many bioactive compounds of health interest such as alkaloids. The present study aims to characterize the alkaloids of young inermis cladodes (nopals) of Algerian Opuntia ficus-indica, and to evaluate their in vitro antioxidant and cytotoxic activities. The alkaloid extraction yield was remarkably low $(0.59 \%)$. The GC-MS analysis demonstrated the presence of seventeen alkaloids such as Neronin and Glucobrassicin. Assessment of alkaloid antioxidant activity showed a significant DPPH scavenging capacity, a medium reducing power and a weak inhibition of $\beta$-carotene bleaching. The nopal alkaloids had no cytotoxic effect on the viability of the hepatic cancer cell line HepG2, or even after inhibition of CYP enzymes. However, their presence can significantly induce the overproduction of reactive species and lead to the loss of mitochondrial membrane potential $\Delta \psi \mathrm{m}$. The purification of these alkaloids, the rational choice of the doses and the understanding of their pharmacological mechanism are obviously one of the key steps to identify the overall therapeutic potential of these nopals.
\end{abstract}

Keywords: Opuntia ficus-indica, Nopal, Alkaloids, Antioxidant, Cytotoxic

\section{How to cite this:}

Moussaoui B, Rahali A, Hamed D, Guemou L, Riazi A, 2022. Antioxidant and cytotoxic activities of alkaloids extracted from inermis nopals of Algerian Opuntia ficus-indica (L). Asian J. Agric. Biol. 2022(2): 202105231. DOI: https://doi.org/10.35495/ajab.2021.05.231

This is an Open Access article distributed under the terms of the Creative Commons Attribution 3.0 License. (https://creativecommons.org/licenses/by/3.0), which permits unrestricted use, distribution, and reproduction in any medium, provided the original work is properly cited.

\section{Introduction}

The cactus Opuntia ficus-indica (L.) is an invasive drought-tolerant plant natively from desert areas of Central America. This species is widespread over the whole world including in the Mediterranean Basin as it is adapted to its climate (Iacopetta et al., 2021;
Sciacca et al., 2021). The Opuntia branches, commonly called cladodes, have a paddles shape with a waxy coverage to prevent water loss by perspiration, and ensure the synthetic function of the plant (Sciacca et al., 2021). The Recent literature background have considered the Opuntia cladodes, especially at young age or nopals, as a source of 
active nutrients and phytochemicals like mucilages, pectins, cellulose, hemicellulose, lignin, sterols, vitamins, polyphenols and alkaloids. These substances are able to provide consumer well-being and high added value to pharmaceutical, nutraceutical and food products (Iacopetta et al., 2021; Sciacca et al., 2021). In North Africa, South and Central America, the tender nopals are used as vegetables or in folk medicine to treat many diseases such as cancer (Liguori et al., 2020; Iacopetta et al., 2021). The alkaloids are biological organo-cyclic, nitrogencontaining compounds, belonging usually to the same family of plants, since the biosynthetic pathways are often similar (Yubin et al., 2014). Despite the strong toxicity of many of these compounds, they have a significant pharmacological activity shown by their wide use in herbal medicine or manufacture of pharmaceuticals (Petruczynik, 2012). To our knowledge, this study is the first contribution to the determination of inermis nopal alkaloids of Opuntia ficus-indica and their antioxidant and cytotoxic activity. Highlighting the health benefits of inermis cladodes could lead to the development of prickly pear cultivation in the country and to a greater popularization of the interest of its consumption.

\section{Material and Methods}

\section{Chemicals and reagents Plant material}

The young spinless nopals of Opuntia ficus-indica (less than 3 months), with 12 to $20 \mathrm{~cm}$ length and 6 to $9 \mathrm{~cm}$ width were collected in November 2017 from wild subjects in Tissemsilt region located in West Algeria (35 $36^{\circ} 28.001^{\prime \prime} \mathrm{N}$ and $\left.1^{\circ} 48^{\prime} 40^{\prime \prime} \mathrm{E}\right)$. The identification of the plant was done at the Faculty of natural Science and Life at the University of Mostaganem-Algeria. The samples are then cleaned, disinfected with $10 \%(\mathrm{w} / \mathrm{v})$ sodium hypochlorite solution, and washed with distilled water before being dried and frozen until use.

\section{Reagents}

Methanol, ethanol, sulfuric acid (98\%), trichloroacetic acid $(\geq 98 \%)$, petroleum ether, anhydrous ammonia ( $\geq 99.95 \%)$, dichloromethane, chloroform, iron (III) chloride $\left(\mathrm{FeCl}_{3}\right)$, sodium sulphate $\left(\mathrm{Na}_{2} \mathrm{SO}_{4}\right)$, sodium citrate $\left(\mathrm{Na}_{3} \mathrm{C}_{6} \mathrm{H}_{5} \mathrm{O}_{7}\right)$, 3(4,5-dimethylthiazol-2-yl) -2,5-diphenyl tetrazolium (MTT), neutral red (NR), 2 ', 7'- dichlorodihydrofuorescein diacetate (DCFH-DA), tetramethylrhodamine ethyl ester (TMRE) all of analytical grade were obtained from Sigma Aldrich (St. Louis, MO, USA). Potassium hexacyanoferrate $\left[\mathrm{K}_{3} \mathrm{Fe} \quad(\mathrm{CN})_{6}\right], \quad$ 2,2-diphenyl-2-picryl-hydrazyl (DPPH), Ascorbic acid, $\beta$-carotene, linoleic acid, Triton X-100, Dimethyl sulfoxide (DMSO), Dulbecco's Modified Eagle's Medium (DMEM), metyrapone, quinidine and Hanks' Balanced Salt Solution (HBSS) of biochemical reagent grade were purchased from Merck Millipore (Darmstadt, Germany).

\section{Preparation of alkaloids extract}

The nopal samples were cut into thin slices, dried at $40^{\circ} \mathrm{C} / 7$ days, ground at $1000 \mathrm{rpm}$ and sieved through mesh of $0.85 \mathrm{~mm}$. The obtained fine powder with homogeneous particle size was stored in an airtight jar protected from light. The alkaloids were extracted according to the method of Bruneton (1999). Briefly, $100 \mathrm{~g}$ of nopal powder defatted for $3 \mathrm{~h}$ with petroleum ether $(250 \mathrm{~mL})$ under stirring at room temperature, is alkalinized with $40 \mathrm{~mL}$ of ammonia $(0.5 \mathrm{~N})$ for $8 \mathrm{~h}$ then extracted in Soxhlet apparatus using dichloromethane $(250 \mathrm{~mL})$ for 3 to $4 \mathrm{~h}$. The crude extract underwent, therefore, three purifications with sulfuric acid $(0.5 \mathrm{~N})(3 \times 150 \mathrm{~mL})$. The collected liquid fractions were alkalinized to $\mathrm{pH}=9$ with ammonia solution $(0.5 \mathrm{~N})$ and exhausted three times with chloroform $(3 \times 150 \mathrm{~mL})$. The recovered organic fractions were dried over sodium sulphate and freed from solvent. After cooling, the dry residue represents the total alkaloids, where its yield was calculated as follows:

$$
\text { Yield }(\%)=\frac{\text { Dry extract weight }}{\text { Dry sample weight }} X 100
$$

\section{CG-MS analysis of alkaloids}

The CG-MS analysis of nopal alkaloids was carried out by direct injection of $0.3 \mu \mathrm{L}$ in a split mode (1:100) into a gas chromatograph (Brucker Scion SQ, Goes, Netherlands) equipped with a capillary column DB-5 (25m length $x \quad 0.22 \mathrm{~mm}$ internal diameter $\mathrm{x}$ $0.25 \mu \mathrm{m}$ film thickness) and coupled to the Mass Spectrum instrument (SQ: Single Quadrupole) operating in electronic impact (EI) at $70 \mathrm{eV}$, scanning the $m / z$ 35-600 range. The initial temperature of the column was set at $200{ }^{\circ} \mathrm{C}$ for $0.8 \mathrm{~min}$ and then increased to $250{ }^{\circ} \mathrm{C}$ by a rate of $10^{\circ} \mathrm{C} / \mathrm{min}$ to be kept 
at this temperature for $24 \mathrm{~min}$. The flow rate of helium as carrier gas was $1 \mathrm{~mL} / \mathrm{min}$ while the injector temperature was $250^{\circ} \mathrm{C}$. The mass spectra of the compounds were compared with those of the NIST library and the identity of the nopal alkaloids was revealed by reviewing the literature.

\section{Determination of the antioxidant activity DPPH radical-scavenging activity}

The test with 2,2-diphenyl-2-picryl-hydrazyl (DPPH) was carried out using the Blios (1958) method. A volume of $1 \mathrm{~mL}$ of the alkaloids extract at different concentrations $(31.25,62.50,125$ and $250 \mu \mathrm{g} / \mathrm{mL})$ was mixed with $1 \mathrm{~mL}$ of the $0.06 \mathrm{mM}$ ethanolic DPPH solution as free radical source, then left 30 min at $27^{\circ} \mathrm{C}$ in the dark. After that, the absorbance was recorded at $517 \mathrm{~nm}$ against a negative control free of any alkaloids extract (substituted by pure ethanol). Ascorbic acid (positive control) was used as a reference in the same concentration range. All the analyses were done three times in triplicate. Inhibition efficiency rate (IE \%) of the DPPH radical activity was calculated as follows:

$$
\mathrm{IE} \%=100 \times \frac{\mathrm{A}_{\text {(negative control) }}-\mathrm{A}_{\text {(sample) }}}{\mathrm{A}_{\text {(negative control) }}}
$$

Where: IE\%: inhibition efficiency, A (negative control): the absorbance of the negative control, A (sample): the absorbance of alkaloids extract or ascorbic acid. Moreover, the IC50 represents the concentration of alkaloids or ascorbic acid providing $50 \%$ of the scavenging effect, and it's deduced from the graph [inhibition efficiency rate $=\mathrm{f}$ (concentration)].

\section{Ferric reducing antioxidant power (FRAP)}

FRAP of Algerian nopal alkaloids was determined using the modified method of Oyaizu (1986). $200 \mu \mathrm{L}$ of sample solution at different concentrations (15.75, $62.50,125$ and $250 \mu \mathrm{g} / \mathrm{mL}$ ) were mixed with $500 \mu \mathrm{L}$ of $0.2 \mathrm{M}$ phosphate buffer (pH 6.6) and $500 \mu \mathrm{L}$ of $1 \%$ $(\mathrm{w} / \mathrm{v})$ potassium hexacyanoferrate $\left[\mathrm{K}_{3} \mathrm{Fe}(\mathrm{CN})_{6}\right]$. The mixture was heated at $50^{\circ} \mathrm{C} / 20 \mathrm{~min}$ in a water bath and $500 \mu \mathrm{L}$ of $10 \%(\mathrm{w} / \mathrm{v})$ trichloroacetic acid were added to it, before centrifugation at 3000rpm /10 min. Subsequently, $500 \mu \mathrm{L}$ of supernatant were mixed with $500 \mu \mathrm{L}$ of distilled water and $100 \mu \mathrm{L}$ of $1 \%$ (w/v) $\mathrm{FeCl}_{3}$ freshly prepared. Absorbance was measured at $700 \mathrm{~nm}$ against a negative control where the alkaloids extract was substituted with methanol.
The ascorbic acid represented the positive control. The analysis is based on the direct linear relationship between the absorbance and the FRAP and was repeated three times in triplicate.

\section{$\beta$-carotene bleaching by linoleic acid assay}

This assay was performed according to Kartal et al. (2007) method. $\beta$-carotene $(0.5 \mathrm{mg})$ and linoleic acid $(25 \mu \mathrm{L})$ were emulsified in $1 \mathrm{ml}$ of chloroform and $200 \mathrm{mg}$ of Tween 40. After chloroform evaporation, $100 \mathrm{~mL}$ of oxygen-saturated distilled water were added and the resulting emulsion was vigorously shacked. A volume of $350 \mu \mathrm{L}$ of the alkaloids extract at different concentrations (15.75, 62.50, 125 and 250 $\mu \mathrm{g} / \mathrm{mL}$ ), or of the reference antioxidant, ascorbic acid, at a concentration of $250 \mu \mathrm{g} / \mathrm{mL}$ was added to $2.5 \mathrm{~mL}$ of the previous emulsion and the whole was incubated at $50^{\circ} \mathrm{C}$. The negative control, free of alkaloids extract or ascorbic acid, was run in the same conditions.

The decolorization kinetics of the emulsion was monitored at $490 \mathrm{~nm}$ at $15 \mathrm{~min}$ intervals for $2 \mathrm{~h}$. The antioxidant activity of alkaloids was calculated as follows:

$$
\mathrm{AA}=100 \mathrm{X}\left[1-\left(\frac{\mathrm{AE} 0-\mathrm{AE} 120}{\mathrm{AC} 0-\mathrm{AC} 120}\right)\right]
$$

With: $\mathrm{AE}_{0}$ and $\mathrm{AE}_{120}$ : Absorbance of samples tested at $0 \mathrm{~min}$ and $120 \mathrm{~min}, \mathrm{AC}_{0}$ and $\mathrm{AC}_{120}$ : Absorbance of the negative control at 0 and $120 \mathrm{~min}$, respectively.

\section{Cytotoxic activity}

\section{Nature, origin and cultivation technic of HepG2 tumor cells}

The human hepatocytes of the cancerous line (HepG2) (CESPU, CRL, Gandra, Portugal) were cultured in $75 \mathrm{~mL}$ flasks containing the Dulbecco's Modified Eagle's Medium (DMEM) high glucose supplemented with $10 \%(\mathrm{v} / \mathrm{v})$ heat inactivated fetal bovine serum (HI-FBS) and $1 \%(\mathrm{v} / \mathrm{v})$ of antibiotic solution containing $10.000 \mu \mathrm{g} / \mathrm{mL}$ of streptomycin and $10.000 \mathrm{U} / \mathrm{mL}$ of penicillin (Dias da Silva et al., 2015). HepG2 were kept at $37{ }^{\circ} \mathrm{C}$ in a humidified atmosphere $\left(5 \% \quad \mathrm{CO}_{2}-95 \%\right.$ air) with a change of culture medium every 2 to 3 days. When cell confluence reached $70-80 \%$, cultures were trypsinized (0.25\%: w/v trypsin/1mM EDTA) and could be subcultured for a maximum of 10 passages (Dias da Silva et al., 2015). 


\section{Choice of alkaloids doses and duration of their exposure to HepG2 tumor cells.}

To carry out the cytotoxicity tests, the cells are inoculated at a density of $8.10^{4}$ cells/well, in 96-well microplates at volumes of $100 \mu \mathrm{L}$ of complete culture medium, and then incubated under the above conditions for 24h (Dias da Silva et al., 2015). The following day, the cells are exposed to $100 \mu \mathrm{L}$ of alkaloids at a range of concentrations of $0.25,0.5$ and $1 \mathrm{mg} / \mathrm{mL}$ in the same culture medium devoid of FBS. The alkaloids extract was freshly prepared in dimethylsulfoxide (DMSO) in a way that its concentration never exceeds $1 \%(\mathrm{v} / \mathrm{v})$ in the exposure medium (Dias da Silva et al., 2015). The solvent control (DMSO solution) and the negative control (cell culture without alkaloids) were run in parallel with the incubation of the nopal alkaloids in all tests (Dias da Silva et al., 2015).

Evaluation of the HepG2 tumor cell viability by the reduction of 3- (4,5-dimethylthiazol-2-yl) -2,5diphenyl tetrazolium $M T T$

This assay was performed following the protocol described by Dias da Silva et al. (2015). A sample of 24-hour young culture of HepG2 cells in the presence of nopal alkaloids was added to $100 \mu \mathrm{L}$ of a fresh solution of MTT prepared in Hanks' Balanced Salt Solution (HBSS) $(0.5 \mathrm{mg} / \mathrm{mL})$. After incubation of the plates at $37{ }^{\circ} \mathrm{C}$ for $30 \mathrm{~min}$, the formazan crystals formed were dissolved in $100 \mu \mathrm{L}$ of DMSO after MTT solution removal. After $15 \mathrm{~min}$ of shaking, the absorbance was recorded at 550nm in a BioTek SynergyTM HT plate reader (Vermont, USA). Each dose of nopal alkaloids was tested three times in triplicate in the dark in order to avoid photoalteration of MTT. The graph was presented as percentage of cell proliferation rate as a function of alkaloids concentration $(\mathrm{mg} / \mathrm{mL})$. Triton X-100 (1\%: $\mathrm{v} / \mathrm{v})$ represented the positive control.

\section{Assessment of the viability of HepG2 tumor cells} by the lysosomal inclusion of neutral red (NR)

To provide additional data about the effect of alkaloids of Algerian nopals on HepG2 cells viability, the neutral red uptake test cited by Arbo et al. (2014) was performed. After $24 \mathrm{~h}$ of incubation of the hepatocytes inoculated on 96-well plates in the presence of alkaloids, the exposure medium was substituted by $100 \mu \mathrm{L}$ of NR solution $(50 \mu \mathrm{g} / \mathrm{mL}$ in HBSS). The hepatocytes were incubated $30 \mathrm{~min}$ at 37 ${ }^{\circ} \mathrm{C}$ in a humidified $5 \% \mathrm{CO}_{2}$ atmosphere to allow dye incorporation by viable cell lysosomes. Afterward, tumor cells were washed twice with $200 \mu \mathrm{L}$ of HBSS to remove the extracellular NR, then lysed with 100 $\mu \mathrm{L}$ of lysis mixture (ethanol: glacial acetic acid: distilled water: 50/1/49: V/V/V). Absorbance was measured at $540 \mathrm{~nm}$ in a BioTek SynergyTM HT Multiwell Plate Reader (BioTek Instruments, Vermont, USA). Triton X-100 at 1\% (v/v) represents the positive control. The results were expressed as a percentage of negative control and graphically illustrated.

\section{Assessment of the viability of HepG2 tumor cells after inhibition of cytochrome $\mathbf{P 4 5 0}$}

In order to assess the influence of cytochrome P450 (CYP) on the toxicity of nopal alkaloids towards the tumor cells HepG2, the CYP2E1 and CYP2D6 isoforms of HepG2 cells were inhibited before and during exposure to this nopal alkaloids extract; and then, cell viability was evaluated subsequently using the MTT assay (Dias da Silva et al., 2015). The HepG2 were incubated for $1 \mathrm{~h}$ with $100 \mu \mathrm{L}$ of CYP inhibitor solution containing $500 \mu \mathrm{M}$ metyrapone (CYP2E1 inhibitor) and $10 \mu \mathrm{M}$ quinidine (CYP2D6 inhibitor). The inhibitor concentration has been carefully chosen as to induce inhibition without causing cytotoxicity. This mixture (HepG2 cells/inhibitors) was then co-incubated with alkaloids for $24 \mathrm{~h}$ at $37^{\circ} \mathrm{C}$. Hepatocytes viability was assessed by MTT test described above, and the results were normalized to Triton X-100 (1\%) and negative control. Inhibitory controls (inhibitors alone in culture medium) were compared with negative control to confirm the independence of these treatments from the cytotoxicity results (Dias da Silva et al., 2015).

\section{Determination of the level of reactive oxygen species (ROS) and nitrogen species (NOS)}

The intracellular production of ROS and RNS was observed using the fluorescence assay of 2 ', 7'dichlorodihydrofuorescein diacetate (DCFH-DA) described by Dias da Silva et al. (2015). Since DCFH-DA is not water soluble, it was firstly prepared in DMSO at $4 \mathrm{mM}$ and adjusted in fresh culture medium to the desired concentration (DMSO must not exceed $0.05 \%: \mathrm{v} / \mathrm{v}$ as final concentration). The tumor cells seeded on plates of 96-wells were exposed to $100 \mu \mathrm{L}$ of DCFH-DA $(10 \mu \mathrm{M})$ in the dark at $37{ }^{\circ} \mathrm{C}$ for $30 \mathrm{~min}$. After rinsing with HBSS, the cells were incubated with alkaloids at $37^{\circ} \mathrm{C}$ for $24 \mathrm{~h}$. 
The fluorimeter BioTek SynergyTM HT (Vermont, USA), set at $485 \mathrm{~nm}$ and $530 \mathrm{~nm}$ as excitation and emission, was used to record the fluorescence. The acquired data were normalized to the conditions of the negative control (cell culture medium only).

\section{Determination of mitochondrial membrane potential $(\Delta \Psi \mathrm{m})$}

The inclusion of positively charged dye tetramethylrhodamine ethyl ester (TMRE), made only by active mitochondria, was used to assess their membrane integrity. According to Dias da Silva et al. (2015), hepatocytes co-incubated with alkaloids of Algerian nopals on 96-well plates, were freed from culture medium and washed twice with HBSS (exempt of magnesium or calcium). The cells were subsequently added with $100 \mu \mathrm{L}$ of fresh TMRE (2 $\mu \mathrm{M})$ to be maintained at $37{ }^{\circ} \mathrm{C}$ for $30 \mathrm{~min}$ in dark. After incubation, free magnesium or calcium HBSS was used to wash HepG2 cells two times before recording the fluorescence using a BioTek SynergyTM HT fluorescence microplate reader (Vermont, USA). Excitation and emission wavelengths were $544 \mathrm{~nm}$ and $590 \mathrm{~nm}$, respectively; while the data received were normalized to negative controls.

\section{Statistical analysis}

The results are expressed as means \pm standard error of the mean (SD) of three determinations in triplicate. One-way analysis of variance (ANOVA) was performed using STATISTICA software (version 6.1, StatSoft, Tulsa, OK, USA). The differences between means were considered as significant by Tukey's test at $\mathrm{p}<0.05$.

\section{Results and Discussion}

\section{Alkaloids content}

In this study, the GC-MS chromatogram of different alkaloids of Algerian Opuntia nopals extract is shown in figure 1. The chemical characteristics of the seventeen alkaloids detected (i.e exact mass and formula) are reported in table 1. According to Shedbalkar et al. (2010), the production of alkaloids is a characteristic feature of Cactaceae family. The presence of alkaloids in Opuntia cladodes was also reported by Msaddak et al. (2017). The nopal alkaloids content was about $596.6 \pm 8.71 \mathrm{mg} / 100 \mathrm{~g}$ Dry weight (DW) (Table 2). This minor low extraction yield of alkaloids in nopals has also been reported by Yubin et al. (2014) as a problem of traditional separation and purification technology of alkaloids. Algerian Opuntia nopals contain different alkaloid classes, including derivatives of isoquinoline (compound number 2 named Debrisoquine, and compound 3), imidazole (compound 4), imidapyrazole (compound number 9) and pyrazoloBenzothiazole (compound number 5). We identified also pyridine alkaloids (compounds 7 and 13), indole alkaloids (compound 8 or Glucobrassicin and compound 15), phenyl alkaloids (compounds 10, 11 and 16) and steroid alklaoids (compounds 6, 12 and 14). In addition, we found the lactone alkaloids (compound 1 called Neronin) and pteridine alkaloids (compound number 17).

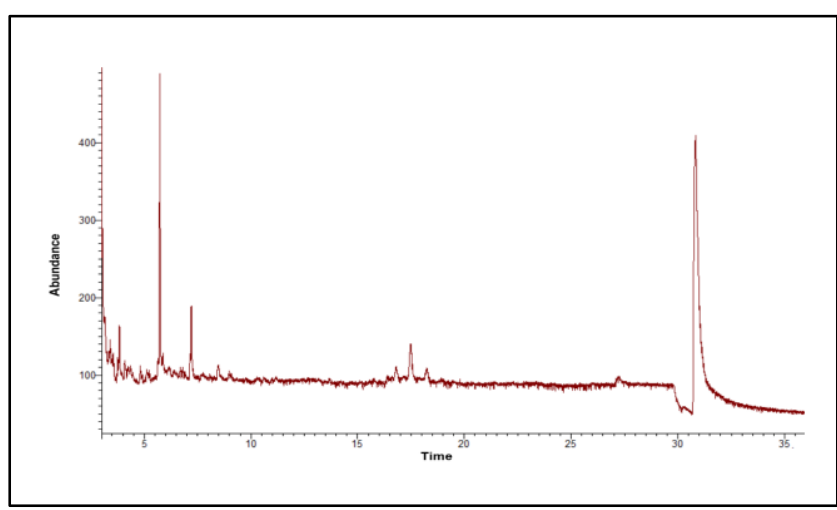

Figure-1: GC-MS of alkaloids extract of Algerian Opuntia nopals (CG: injection volume: $0.3 \mu \mathrm{L}$, split mode 1:100, helium flow rate : $1 \mathrm{~mL} / \mathrm{min}$, column temperature: $200{ }^{\circ} \mathrm{C} / 0.8 \mathrm{~min}$, increased to $250{ }^{\circ} \mathrm{C} / 24 \mathrm{~min}$ by a rate of $10^{\circ} \mathrm{C} / \mathrm{min}$, MS: SQ, EI: 70eV, $\mathrm{m} / \mathrm{z}$ 35-600).

\section{Antioxidant activity}

In order to have a broad knowledge about the overall in vitro antioxidant power of alkaloids obtained from Algerian nopals, different methods such as DPPH, reducing power and $\beta$-carotene bleaching were used herein. 
Table-1: The alkaloids identified in the extract of nopals.

\begin{tabular}{|c|c|c|c|c|}
\hline $\mathbf{N}^{\mathbf{0}}$ & Name & $\mathbf{R}_{\mathrm{t}}$ (min.) & Formula & Exact mass \\
\hline 1 & Neronine, $4 \beta, 5$-dihydro- & 8.804 & $\mathrm{C}_{18} \mathrm{H}_{21} \mathrm{NO}_{6}$ & 347.136887 \\
\hline 2 & 2(1H)-Isoquinolinecarboximidamide, 3,4-dihydro- & 8.936 & $\mathrm{C}_{10} \mathrm{H}_{13} \mathrm{~N}_{3}$ & 175.110948 \\
\hline 3 & $\begin{array}{l}\text { Morphinan-4,5-epoxy-3,6-di-ol, 6-[7-nitrobenzofurazan-4- } \\
\text { yl]amino- }\end{array}$ & 9.027 & $\mathrm{C}_{26} \mathrm{H}_{27} \mathrm{~N}_{5} \mathrm{O}_{6}$ & 505.196133 \\
\hline 4 & $\begin{array}{l}\text { Decahydronaphtho[2,3-b]furan-2-one, 3-[[2-(1H-imidazol-4- } \\
\text { yl)ethylamino]methyl]-8a-methyl-5-methylene- }\end{array}$ & 9.159 & $\mathrm{C}_{20} \mathrm{H}_{29} \mathrm{~N}_{3} \mathrm{O}_{2}$ & 343.225977 \\
\hline 5 & $\begin{array}{l}\text { 2-Benzothiazol-2-yl-4-cyclopentylaminomethylene-5-methyl-2,4- } \\
\text { dihydro-pyrazol-3-one }\end{array}$ & 9.194 & $\mathrm{C}_{17} \mathrm{H}_{18} \mathrm{~N}_{4} \mathrm{OS}$ & 326.120132 \\
\hline 6 & 17a-Methyl-3 $\beta$-methoxy-17a-aza-D-homoandrost-5-ene-17-one & 9.311 & $\mathrm{C}_{21} \mathrm{H}_{33} \mathrm{NO}_{2}$ & 331.25113 \\
\hline 7 & $\begin{array}{l}\text { 3-Pyridinecarboxylic acid, 2,7,10-tris(acetyloxy)- } \\
\text { 1,1a,2,3,4,6,7,10,11,11a-decahydro-1,1,3,6,9-pentamethyl-4-oxo- } \\
\text { 4a,7a-epoxy-5H-cyclopenta[a] cyclopropa[f]cycloundecen-11-yl } \\
\text { ester,[1aR- } \\
\left.\left(1 \mathrm{aR} *, 2 \mathrm{R}^{*}, 3 \mathrm{~S}^{*}, 4 \mathrm{aR} *, 6 \mathrm{~S}^{*}, 7 \mathrm{~S}^{*}, 7 \mathrm{aS} *, 8 \mathrm{E}, 10 \mathrm{R}^{*}, 11 \mathrm{R}^{*}, 11 \mathrm{aS} *\right)\right] \text { - }\end{array}$ & 9.422 & $\mathrm{C}_{32} \mathrm{H}_{39} \mathrm{NO}_{10}$ & 597.257397 \\
\hline 8 & Glucobrassicin & 9.499 & $\mathrm{C}_{16} \mathrm{H}_{20} \mathrm{~N}_{2} \mathrm{O}_{9} \mathrm{~S}_{2}$ & 448.061022 \\
\hline 9 & Pyrazole[4,5-b]imidazole, 1-formyl-3-ethyl-6- $\beta$-d-ribofuranosyl- & 9.676 & $\mathrm{C}_{12} \mathrm{H}_{16} \mathrm{~N}_{4} \mathrm{O}_{5}$ & 296.11207 \\
\hline 10 & 2-Hexanone, (2,4-dinitrophenyl)hydrazone & 9.39 & $\mathrm{C}_{12} \mathrm{H}_{16} \mathrm{~N}_{4} \mathrm{O}_{4}$ & 280.117155 \\
\hline 11 & $\begin{array}{l}\text { Benzenepropanoic acid, } \alpha \text {-[(2,4-dinitrophenyl)hydrazono]-4- } \\
\text { hydroxy- }\end{array}$ & 10.117 & $\mathrm{C}_{15} \mathrm{H}_{12} \mathrm{~N}_{4} \mathrm{O}_{7}$ & 360.070599 \\
\hline 12 & Pseudosolasodine diacetate & 10.428 & $\mathrm{C}_{31} \mathrm{H}_{49} \mathrm{NO}_{4}$ & 499.36616 \\
\hline 13 & $\begin{array}{l}\text { 2,7-Diphenyl-1,6-dioxopyridazino[4,5:2',3']pyrrolo[4',5'- } \\
\text { d]pyridazine }\end{array}$ & 12.858 & $\mathrm{C}_{20} \mathrm{H}_{13} \mathrm{~N}_{5} \mathrm{O}_{2}$ & 355.106924 \\
\hline 14 & Pregn-4-ene-3,20-dione, 17,21-dihydroxy-, bis(O-methyloxime) & 12.949 & $\mathrm{C}_{23} \mathrm{H}_{36} \mathrm{~N}_{2} \mathrm{O}_{4}$ & 404.267508 \\
\hline 15 & Aspidofractinin-3-ol, 17-methoxy-, $(2 \alpha, 5 \alpha)$ - & 30.684 & $\mathrm{C}_{20} \mathrm{H}_{26} \mathrm{~N}_{2} \mathrm{O}_{2}$ & 326.199429 \\
\hline 16 & Cathine & 30.78 & $\mathrm{C}_{9} \mathrm{H}_{13} \mathrm{NO}$ & 151.099714 \\
\hline 17 & Pterin-6-carboxylic acid & 31.42 & $\mathrm{C}_{7} \mathrm{H}_{5} \mathrm{~N}_{5} \mathrm{O}_{3}$ & 207.039239 \\
\hline
\end{tabular}

\section{DPPH radical-scavenging assay}

DPPH radical-scavenging activity of the nopal alkaloid extract is dose-dependent. The IC50 of the antioxidant activity of alkaloids extract was higher $(119.40 \mu \mathrm{g} / \mathrm{mL})$, but quite comparable to that of ascorbic acid (102.99 $\mu \mathrm{g} / \mathrm{ml})$ (Table 2). The IC50 noted in this study is ten times lower than that found by Toure et al. (2015), touching the bar of $1208.75 \pm$ $179.21 \mu \mathrm{g} / \mathrm{mL}$ for extracts of Moroccan cladodes. The structure of Algerian nopal alkaloids, almost devoid of free phenolic groups on their skeleton and having only a limited number of $\mathrm{OH}$ groups, is directly responsible for their moderate anti-free radical effect compared to ascorbic acid (Račková et al., 2004). It can be assumed that $\mathrm{NH}_{2}, \mathrm{OCH}_{3}$ and especially $\mathrm{OH}$ groups still existing in the structure of the identified alkaloids, behaved as hydrogen donors in favor of the oxidized form of DPPH (Al-Sehemi and Irfan, 2017). According to Račková et al. (2004), the presence of free phenolic groups on the alkaloid backbone has been found to be crucial for good intrinsic antioxidant activity.

Table-2: Extraction yield, IC50 of DPPH scavenging and IC50 of ferric reduction FRAP by nopal alkaloids and ascorbic acid.

\begin{tabular}{|l|c|c|c|c|}
\hline & Alkaloids & $\begin{array}{c}\text { DPPH } \\
(\mathbf{I C 5 0 )} \\
(\boldsymbol{\mu g} / \mathbf{m l})\end{array}$ & $\begin{array}{c}\text { FRAP } \\
(\mathbf{I C 5 0}) \\
(\boldsymbol{\mu g} / \mathbf{m l})\end{array}$ \\
\hline $\begin{array}{l}\text { Content } \\
(\mathrm{mg} / 100 \mathrm{~g} \text { DW) }\end{array}$ & $596.60 \pm 8.71$ & Alkaloids & 119.40 & 915.75 \\
\hline Yield $(\%)$ & 0.59 & $\begin{array}{c}\text { Ascorbic } \\
\text { acid }\end{array}$ & 102.22 & 143.46 \\
\hline
\end{tabular}

DW: dry weight. The content of alkaloids is the mean \pm SD of three measurements.

Likewise, the scavenging mechanism of alkaloids resulting from hydrogen donating depends on their structural conformation and increases with the degree of hydroxylation (Račková et al., 2004). These researchers stated the degree of hydroxylation as one of the main parameters of influence on alkaloids trapping effect, in which the dihydroxyls 
(magnoflorine) are more effective than those carrying an unsubstituted - $\mathrm{OH}$ group (jatrorrhizine), while those characterized by the absence of the group carrying the extractable hydrogen (berberine) showed only negligible activity. $\mathrm{Ng}$ et al. (2018) also found that certain alkaloids are bad anti-free radicals as a consequence of their weakness in releasing hydrogen.

\section{Ferric Reducing Antioxidant Power (FRAP)}

In this assay, the FRAP of alkaloids reflect their antioxidant potential. The reducing ability converted free radicals into more stable compounds, or produced active antioxidant molecules. To some extent, there is a direct relationship between the alkaloids ferric reducing power and absorbance. According to the obtained results (Fig. 2A and Table 2 ), the reducing power of Algerian nopal alkaloids follow a dose-dependent increase with a limited effect (IC50 $=915.75 \mu \mathrm{g} / \mathrm{mL}$ ) compared to ascorbic acid (IC50=143.46 $\mu \mathrm{g} / \mathrm{mL}$ ). The maximum reducing activity of alkaloids (O.D $=0.222 \pm 0.03)$ was observed at $250 \mu \mathrm{g} / \mathrm{mL}$, a much lower absorbance than that registered for the positive standard at the same concentration (O.D $=0.818 \pm 0.02)$. The difference in reducing power of alkaloids and standard only became significant $(p<0.05)$ after a concentration of $125 \mu \mathrm{g} / \mathrm{mL}$. The reducing power is related to the molecular structure of alkaloids. In this regard, $\mathrm{Ng}$ et al. (2018) showed that the high electron density of the side chain of isoprene unit of the alkaloid mahanimbine allowed better FRAP; it acts as a good electron donor to purge radical species. In addition, this FRAP depends also on the position and the number of hydroxyl groups according to Khamtache-Abderrahim et al. (2016); which could partly explain the low reducing power of nopal alkaloids analyzed in this work, given the very small number of these functional groups in their structure. The moderate donation of electrons by alkaloids could also be due to the antagonism between groups with low ionization potential like $\mathrm{CH}_{3}, \mathrm{OCH}_{3}$ and $\mathrm{NH}_{2}$, which easily lost a single electron, and groups with high ionization potential present concomitantly in the chemical structure (Al-Sehemi and Irfan, 2017).

\section{B-carotene bleaching}

This test is used to evidence the protective effect of alkaloids against peroxide radicals and give complementary information to those provided by DPPH radical scavenging and reducing power. The $\beta$-carotene bleaching test simulates the lipid peroxidation in biological membranes. It exploits the peroxide radicals resulting from linoleic acid oxidation to abstract the hydrogen of the $\beta$-carotene chromophore, and therefore, to extinguish its characteristic orange color which can be followed spectrophotometrically. However, the presence of antioxidants decreases the extent of $\beta$-carotene destruction and bleaching by neutralization of linoleate free radicals (Alam et al., 2015; Dib et al., 2014).
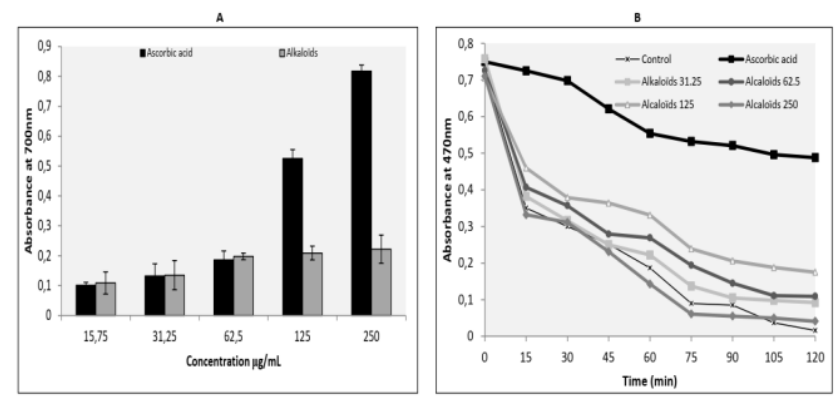

Figure-2: Antioxidant activity of alkaloids and ascorbic acid expressed as (A) Reducing power (FRAP) and (B) Kinetics of $\beta$-carotene bleaching (The results represent means \pm SD of three determinations).

The bleaching kinetics of $\beta$-carotene in the presence and absence of alkaloids and ascorbic acid (standard antioxidant) is shown in figure 2B. A significant increase in the rate of dose-dependent inhibitory effect of $\beta$-carotene bleaching by nopal alkaloids (6.06, 12.97 and $25.24 \%)$ was observed up to their highest concentration $(250 \mu \mathrm{g} / \mathrm{mL})$ beyond which, this effect has become $5.64 \%$. The alkaloids neutralized the hydroperoxide radical and inhibited the oxidation of $\beta$-carotene; but at high concentrations they could turn into oxygen carriers and act as pro-oxidants ( $\mathrm{Ng}$ et al., 2018). The $\beta$ carotene bleaching inhibitory effect of all tested nopal's alkaloid concentrations was significantly lower $(\mathrm{p}<0.05)$ than that of ascorbic acid which reached a maximum of $63.04 \%$. Furthermore, the absorbance is slightly decline in presence of ascorbic acid compared to their important regression in presence of both alkaloid concentrations and negative control. According to the FRAP results of the present study and the findings reported by Ammar et al. (2015), the lack of anti-lipoperoxidation effect of nopal alkaloids could be related to their low electron donation ability. Sundaram et al. (2015) underlined 
the better lipid peroxidation inhibition by electron donor compounds which act as primary and secondary antioxidants. However, several factors seem to modulate the protection of linoleic acid against oxidation, namely the extraction solvent and methods, the concentration of antioxidants and their liposoluble or water-soluble nature (Ammar et al., 2015).

\section{Cytotoxic activity \\ Effect of nopal alkaloids on the viability of HepG2 tumor cells using the MTT method}

MTT method measures the succinate dehydrogenase activity able to convert the yellow soluble MTT into purple insoluble formazan salts. As a result, this enzyme activity can be used as an indicator of the mitochondria metabolic activity and therefore of cell viability. Table 3 shows that there is no significant cytotoxic effect $(p>0.05)$ of all tested nopal alkaloids concentrations towards the HepG2 tumor cells. Contrary to these results, El-Beltagi et al. (2019) observed a decrease in the viability of liver cell line (HepG2) with increasing the concentrations of the ethanolic extract of the pulp and peel of Opuntia fruit $(500,1000,1500,2000,3000 \mu \mathrm{g} / \mathrm{mL})$. These authors linked this cytotoxicity against HepG2 cells to the high concentrations of secondary metabolites as alkaloids in Opuntia extracts. Several factors can be cited to explain this lack of cytotoxicity. At first, the range of doses used may represent a limiting factor for the cytotoxic effect of alkaloids, since Keller et al. (2015) had to multiply ten times the inefficient concentration of the O. ficusindica cladode powder to get an inhibition of preneoplastic colon cells growth. Besides, the same researchers qualify this powder as the less efficient among powders of other Opuntia varieties in protecting normal colon cells against cell death induced by $40 \mu \mathrm{M}$ of 4-hydroxynonenal (HNE), an end product of cytotoxic lipid peroxidation. This observation suggests a probable effect of the intervarietal and inter-station sampling differences on the control of cytotoxic activity of nopal alkaloid extracts. Secondly, the hydrophilic character of nopal alkaloids could be responsible for the absence of toxicity against tumor cells. In a comparative study of the cytotoxic effect of two drugs, Dias da Silva et al. (2017) showed that the most effective is the most lipophilic, since it crossed the cytoplasmic and mitochondrial membranes more easily and reaches the cell target at effective concentrations. These authors suggested that the most hydrophobic molecules stay longer inside the cell and can therefore exert more toxicity. Finally, the resistant feature of liver cancer cells is another reason explaining the weak activity of nopal alkaloids. According to Katanić et al. (2019), human liverderived cancer cells (HepG2) were the most resistant to different extracts of Opuntia flesh, seeds and fruit peel tested at 0.1 to $0.5 \mathrm{mg} / \mathrm{mL}$, compared to colon (LoVo) and breast (MCF-7) cancer cell lines.

\section{Effect of nopals alkaloids on the viability of HepG2 tumor cells evaluated by the neutral red lysosomal inclusion method}

This assay is based on the ability of viable cells to incorporate and bind the weak cationic dye NR, which enters cells by nonionic diffusion and accumulates in lysosomes by interaction with anionic sites in the organelle matrix. Lysosomal integrity, associated concomitantly with NR, is a very sensitive indicator of cell viability (Repetto et al.,2008). In this study, several in vitro tests were used to measure cell viability so as to increase the reliability of the obtained results. The inhibition of HepG2 proliferation in presence of cladode alkaloids based on the NR neutral red absorption technique was insignificant $(p>0.05)$ as shown in Table 3. The NR test confirms the absence of nopals extract effect on the cancer cell line HepG2 noted in the MTT test. However, the comparison of the results obtained for cell viability by reduction of MTT and absorption of $\mathrm{NR}$, can provide information on the relative sensitivity of target organelles after exposure of cells to extracts of Algerian Opuntia nopals (Dias da Silva et al.,2019). The nonlinear relation between the concentration and the effect makes impossible to calculate and compare the IC50 of MTT and NR assays, and leads to choose the mean effects and the maximum effects for this purpose. The mean cytotoxicity induced in lysosomes by alkaloids is greater than that required to damage mitochondria by $1.7 \%$. In the other hand, the comparison of the maximum cytotoxicity of alkaloids in MTT and NR tests, have shown a respective cytotoxic improvement in the latter at a rate of $0.22 \%$. These results indicate that alkaloids target more but very slightly mitochondria than lysosomes. 
Moussaoui Badreddine et al.

Table-3: cytotoxic effect of Algerian nopal alkaloids on HepG2 cancer cells.

\begin{tabular}{|c|c|c|c|c|c|c|c|}
\hline \multicolumn{2}{|c|}{ Assay } & $\underset{\%}{\text { MTT }}$ & $\begin{array}{c}\text { NR } \\
\%\end{array}$ & $\begin{array}{c}\text { CYP2E1 inhibition } \\
\text { (Metyrapone) } \\
\% \\
\end{array}$ & $\begin{array}{c}\text { CYP2D6 inhibition } \\
\text { (Quinidine) } \\
\% \\
\end{array}$ & $\begin{array}{c}\text { ROS/RNS } \\
(\% \text { control })\end{array}$ & $\begin{array}{c}\Delta \psi \mathrm{m} \\
(\% \text { control })\end{array}$ \\
\hline \multicolumn{2}{|c|}{ Control } & 100 & 100 & 100 & 80 & 1 & 1 \\
\hline \multirow{3}{*}{$\begin{array}{c}\text { Alkaloids } \\
(\mathrm{mg} / \mathrm{mL})\end{array}$} & 0.25 & $100.09 \pm 5.79^{n s}$ & $102.64 \pm 7.28^{n s}$ & $100.09 \pm 3.77^{n s}$ & $99.15 \pm 6.04^{n s}$ & $1.49 \pm 0.11^{n s}$ & $0.26 \pm 0.08^{*}$ \\
\hline & 0.5 & $98.59 \pm 9.12^{n s}$ & $98.33 \pm 7.62^{n s}$ & $99.22 \pm 2.87^{n s}$ & $75.23 \pm 5.28^{n s}$ & $0.98 \pm 0.05^{n s}$ & $0.27 \pm 0.03^{*}$ \\
\hline & 1 & $99.14 \pm 2.98^{n s}$ & $101.99 \pm 6.44^{n s}$ & $98.65 \pm 7.18^{n s}$ & $50.05 \pm 4.99^{n s}$ & $0.81 \pm 0.14^{n s}$ & $0.3 \pm 0.05^{*}$ \\
\hline
\end{tabular}

*significant at $p$-value $<0.05, n s$ : non-significant

\section{Effect of nopals alkaloids on the viability of HepG2 tumor cells after inhibition of cytochrome P450}

To evaluate the function of cytochrome $\mathrm{P} 450$ (CYP450) enzymes involved in the metabolism of nopal alkaloids by hepatocytes, HepG2 cells were coincubated with two different isoforms of specific inhibitors of this enzyme, namely metyrapone (inhibitor of CYP2E1) and quinidine (inhibitor of CYP2D6). CYP450 enzymes are involved in phase I of the metabolism of xenobiotics; including drugs, environmental pollutants, and diet products, using many catalytic reactions such as oxygenation, decarboxylation, hydroxylation, dealkylation, epoxidation, C-C bond cleavage and ring opening (Bak et al., 2011; Basheer and Kerem, 2015). The metabolic products of $\mathrm{P} 450$ become more hydrosoluble and available for phase II enzymes, which further increase their solubility and facilitate the elimination of these unwanted xenobiotics (Basheer and Kerem, 2015). Table 3 shows the concentrationresponse obtained after the co-incubation of HepG2 cells with nopal alkaloids and CYP450 inhibitors. Overall, no significant influence $(p>0.05)$ was recorded between the alkaloids and the control $(\mathrm{p}>$ 0.05) after blocking CYP2D6 by quinidine or CYP2E1 by metyrapone. In addition, the variation of the concentration was insignificant ( $p>0.05)$ for the CYP inhibition in both tests. In this work, the independence of the metabolism of Algerian nopal alkaloids form CYP isoforms was noticed. Thus, the alkaloids are more active after inhibition of CYP2D6 than after inhibition of CYP2E1, with a cytotoxic effect of $49.95 \%$ against $1.35 \%$, respectively. This discrepancy could be due to the different metabolic relevance of CYP450 isoforms for each molecule, since some of them might be more metabolized by CYP2D6 than others. Paradoxically, CYP enzymes exhibit simultaneous activity in the metabolic activation and inactivation of numerous environmental compounds and drugs (Lin et al., 2012). The most important CYP450 isoforms such as CYP2D6, involved during phase I of metabolization in the liver, are absent or barely detectable in HepG2 cells (Guo et al., 2011). Thus, the results of Guo et al. (2011) and Lin et al. (2012) confirmed that the limitation of the presence of CYP in these cancer cells compared to normal cells could be considered as a reason for the inactivation and ineffectiveness of secondary metabolites like the nopal alkaloids of this study. Likewise, the under-expression of organic cation transporters (OCT) responsible for the absorption function in the basolateral membrane of immortalized hepatic cells as HepG2 cells, could be responsible for the lack of nopal alkaloids administration and explain partly the non-cytotoxicity of these molecules (Dias da Silva et al., 2015).

\section{Influence of nopal alkaloids on the production of ROS and NOS by HepG2 tumor cells}

The analysis of Table 3 shows that the generation of reactive intermediates RNS/ROS was inversely favored by the increasing concentration of nopal extract. Nopal alkaloids induce overproduction of reactive species with a maximum of $49 \%$ for the lowest concentration $(0.25 \mathrm{mg} / \mathrm{mL})$, while concentrations of 0.5 and $1 \mathrm{mg} / \mathrm{mL}$ gave equal or low levels compared to the control. The production of reactive species is significantly $(\mathrm{p}<0.05)$ more pronounced with $0.25 \mathrm{mg} / \mathrm{mL}$ dose than $1 \mathrm{mg} / \mathrm{mL}$. Recently, scientists have appreciated the dual role of ROS in cancer because, on one hand, these ROS promote pro-tumorigenic signaling, facilitate proliferation, survival, angiogenesis and metastasis as well as adaptation of cancer cells to hypoxia; and on the other hand, they stimulate anti-tumorigenic signaling and induce cancer cell death by oxidative stress (Reczek and Chandel, 2017). Therefore, strategies that target the removal of ROS below the minimum requirement, or their overproduction 
beyond the antioxidant capacity of cancer cells can potentially be effective therapeutic approaches against cancer (Reczek and Chandel, 2017).

Phytochemicals can act as anti/pro-oxidants depending on their doses, cell type, exposure time and the environment in which they are found (Sznarkowska et al., 2017). The specific pro-oxidant effect of Algerian nopal alkaloids can explain the overproduction of reactive species in HepG2 cells. The production of reactive species by stimulation of CYP enzymes also seems very likely for nopal alkaloids. The results suggest that the intrinsic antioxidant machinery of HepG2 cells was exceeded by the oxidative burst caused by alkaloid extract. Nevertheless, this overproduction does not reach lethal rates to make nopal alkaloids toxics against liver cancer cells.

\section{Effect of nopal alkaloids on mitochondrial membrane potential $(\Delta \psi \mathrm{m})$}

The $\Delta \psi \mathrm{m}$ was evaluated in the presence and absence of nopal alkaloids in order to determine their capacity to disrupt the mitochondrial function of HepG2 cells, including ATP generation and calcium buffering effect. A significant mitochondrial depolarization ( $\mathrm{p}$ $<0.05$ ) was recorded for all concentrations (Table 3 ). The mitochondrial inclusion of the TMRE pigment, which reflects the integrity and membrane potential of mitochondria, was decreased by $72.33 \%$ in presence of alkaloids. In other words, the $\Delta \psi \mathrm{m}$ was 3.6 times lower than the control. The results of $\Delta \psi \mathrm{m}$ test are in agreement with the previous observation based on comparison of MTT and NR viability assays, highlighting more deleterious action of nopal alkaloids on mitochondria than on other organelles.

The hyperactivity of cancer cells requires a temporary high production of ATP linked to the overproduction of ROS, which will be followed, therefore, by a reduction in ATP levels, a decrease in the mitochondrial membrane potential $\Delta \psi \mathrm{m}$ and of apoptosis (Wang et al., 2001). The highest ATP depletion was significantly $(\mathrm{p}<0.05)$ concomitant with the highest loss of membrane potential $\Delta \psi \mathrm{m}$ for primary rat hepatocytes (Dias da Silva et al., 2015). However, the loss of potential $\Delta \psi \mathrm{m}$ is not necessarily an early event of apoptosis, and can be attributed to autophagy. In addition, the depletion of cellular energy reserves and the increased formation of ROS/RNS noted in presence of nopal alkaloids, are important mediators of autophagy according to Dias da Silva et al. (2019).

\section{Conclusion}

The results recorded in this work on the bioactivity of seventeen alkaloids identified by GC-MS in Algerian Opuntia nopals, showed a potent free radical scavenging based probably on a good proton donation. In addition, they had a moderate electron liberation but were inefficient as lipoperoxide quenchers. Despite the ineffectiveness of nopal alkaloids against HepG2 cancer cells, the quality of triggering the depolarization of mitochondrial potential and the overproduction of reactive species in these cells was impressive. More experiments are needed to highlight the mechanisms by which nopal alkaloids act on these correlated biological processes.

\section{Acknowledgement}

This work was financially supported by the Algerian ministry of higher education and scientific research (PRFU project number: DO1NO1UN2701201400026

Disclaimer: None.

Conflict of Interest: None.

Source of Funding: Algerian Ministry of Higher Education and Scientific Research.

\section{References}

Alam MN, Biozid MS, Islam MR., Rahman MM, Chowdhury AI and Mazumdar MMU, 2015. Invitro comparative study of Anti-inflammatory and anti-arthritic effects of the methanol extract of Cissus pentagona Roxb and Thunbergia grandiflora Roxb Leaf. J. Pharm. Innov. 4(4): 3942.

Al-Sehemi AG and Irfan A, 2017. Effect of donor and acceptor groups on radical scavenging activity of phenol by density functional theory. Arab. J. Chem.10 : S1703-S1710.

Ammar I, Ennouri M and Attia H, 2015. Phenolic content and antioxidant activity of cactus (Opuntia ficus-indica L.) flowers are modified according to the extraction method. Ind Crops Prod. 64: 97-104.

Arbo MD, Silva R, Barbosa DJ, da Silva DD, Rossato LG, de Lourdes Bastos M and Carmo H, 2014. Piperazine designer drugs induce toxicity in cardiomyoblast $\mathrm{h} 9 \mathrm{c} 2$ cells through 
mitochondrial impairment. Toxicol. Lett. 229 (1): 178-189.

Bak S, Beisson F, Bishop G, Hamberger B, Höfer R, Paquette S and Werck-Reichhart D, 2011. Cytochromes P450. TAB/ASPB. 9. e0144.

Basheer L and Kerem Z, 2015. Interactions between CYP3A4 and dietary polyphenols. Oxid. Med. Cell. Longev. 2015: 854015.

Blios MS, 1958. Antioxidant determinations by the use of a stable free radical. Nature. 26: 11991200.

Bruneton J, 1999. Pharmacognosie, phytochimie, plante médicinale, $\left(3^{\text {rd }}\right.$ éds). Editions Tec \& Doc, Lavoisier, Paris.

Dias da Silva D, Arbo MD, Valente MJ, Bastos ML and Carmo H, 2015. Hepatotoxicity of piperazine designer drugs: Comparison of different in vitro models. Toxicol. In Vitro. 29(5): 987-996.

Dias da Silva D, Ferreira B, Roque Bravo R, Rebelo R, Duarte de Almeida T, Valente MJ, Silva JP, Carvalho F, Bastos ML and Carmo H, 2019. The new psychoactive substance 3methylmethcathinone (3-MMC or metaphedrone) induces oxidative stress, apoptosis, and autophagy in primary rat hepatocytes at humanrelevant concentrations. Arch. Toxicol. 93(9): 2617-2634.

Dias da Silva D, Silva MJ, Moreira P, Martins MJ, Valente MJ, Carvalho F, Bastos ML and Carmo $\mathrm{H}, 2017$. In vitro hepatotoxicity of 'Legal $\mathrm{X}$ ': the combination of 1-benzylpiperazine (BZP) and 1(m-trifluoromethylphenyl) piperazine (TFMPP) triggers oxidative stress, mitochondrial impairment and apoptosis. Arch. Toxicol. 91(3): 1413-1430.

Dib H, Belarbi M, Beghdad MC and Seladji M, 2014. Antioxidant activity of Opuntia ficus-indica flowers phenolic extracts. Int. J. Pharm. Sci. Res. 5: 4574-4582.

El-Beltagi HS, Mohamed HI, Elmelegy AA, Eldesoky SE and Safwat G, 2019. Phytochemical screening, antimicrobial, antiaxidant, anticancer activities and nutritional values of cactus (Opuntia ficus indicia) pulp and peel. Fresenius Environ. Bull. 28(2A): 1534-1551.

Guo L, Dial S, Shi L, Branham W, Liu J, Fang JL, Green B, Deng H, Kaput J and Ning B, 2011. Similarities and differences in the expression of drug-metabolizing enzymes between human hepatic cell lines and primary human hepatocytes. Drug Metab Dispos. 39(3): 528-
538.

Iacopetta D, Baldino N, Caruso A, Perri V, Lupi FR, de Cindio B, Gabriele D and Sinicropi MS, 2021. Nutraceuticals Obtained by $\mathrm{SFE}-\mathrm{CO}_{2}$ from Cladodes of Two Opuntia ficus-indica (L.) Mill Wild in Calabria. Appl. Sci. 11(2): 477.

Kartal N, Sokmen M, Tepe B, Daferera D, Polissiou $M$ and Sokmen A, 2007. Investigation of the antioxidant properties of Ferula orientalis L. using a suitable extraction procedure. Food Chem. 100: 584-589.

Katanić J, Yousfi F, Caruso MC, Matić S, Monti DM, Loukili EH, Boroja $\mathrm{T}$, Mihailovic V, Galgano F, Imbimbo P, Petruk G, Bouhrim M, Bnouham M and Mohammed R, 2019. Characterization of bioactivity and phytochemical composition with toxicity studies of different Opuntia dillenii extracts from Morocco. Food Biosci. 30: 100410.

Keller J, Camaré C, Bernis C, Astello-García M, De la Rosa APB, Rossignol M, Del Socorro Santos Díaz M, Salvayre R, Negre-Salvayre A and Guéraud F, 2015. Antiatherogenic and antitumoral properties of Opuntia cladodes: inhibition of low density lipoprotein oxidation by vascular cells, and protection against the cytotoxicity of lipid oxidation product 4hydroxynonenal in a colorectal cancer cellular model. J. Physiol. Biochem. 71(3): 577-587.

Khamtache-Abderrahim S, Lequart-Pillon M, Gontier E, Gaillard I, Pilard S, Mathiron D, DjoudadKadji H and Maiza-Benabdesselam F, 2016. Isoquinoline alkaloid fractions of Fumaria officinalis: Characterization and evaluation of their antioxidant and antibacterial activities. Ind. Crops Prod. 94: 1001-1008.

Liguori G, Gentile C, Gaglio R, Perrone A, Guarcello R, Francesca N, Fretto S, Inglese P and Settanni L, 2020. Effect of addition of Opuntia ficusindica mucilage on the biological leavening, physical, nutritional, antioxidant and sensory aspects of bread. J. Biosci. Bioeng. 129(2): 184191.

Lin J, Schyschka L, Mühl-Benninghaus R, Neumann J, Hao L, Nussler N, Dooley S, Liu L, Stöckle U, Nussler AK and Ehnert S, 2012. Comparative analysis of phase I and II enzyme activities in 5 hepatic cell lines identifies Huh-7 and HCC-T cells with the highest potential to study drug metabolism. Arch. Toxicol. 86(1): 87-95.

Msaddak L, Abdelhedi O, Kridene A, Rateb M, 
Belbahri L, Ammar E, Nasri M and Zouari N, 2017. Opuntia ficus-indica cladodes as a functional ingredient: bioactive compounds profile and their effect on antioxidant quality of bread. Lipids Health Dis. 16(1): 1-8.

$\mathrm{Ng} \mathrm{RC,} \mathrm{Kassim} \mathrm{NK,} \mathrm{Yeap} \mathrm{YS,} \mathrm{Ee} \mathrm{GCL,} \mathrm{Yazan} \mathrm{SL}$ and Musa KH, 2018. Isolation of carbazole alkaloids and coumarins from Aegle marmelos and Murraya koenigii and their antioxidant properties. Sains Malay. 47(8): 1749-56.

Oyaizu M, 1986. Studies on products of browning reactions: antioxidant activities of products of browning reaction prepared from glucosamine. J. Nutr. 44: 307-315.

Petruczynik A, 2012. Analysis of alkaloids from different chemical groups by different liquid chromatography methods. Cent. Eur. J. Chem. 10(3): 802-835. DOI: 10.2478/s11532-012-0037y.

Račková L, Májeková M, Košt'álová D and Štefek M, 2004. Antiradical and antioxidant activities of alkaloids isolated from Mahonia aquifolium. Structural aspects. Bioorg. Med. Chem. 12(17): 4709-4715.

Reczek CR and Chandel NS, 2017. The two faces of reactive oxygen species in cancer. Annu. Rev. Cancer Biol. 1:79-98

Repetto G, Del Peso A and Zurita JL, 2008. Neutral red uptake assay for the estimation of cell viability/cytotoxicity. Nat. Protoc. 3(7): 1125.

Sciacca F, Palumbo M, Pagliaro A, Di Stefano V, Scandurra S, Virzì N and Melilli MG, 2021. Opuntia cladodes as functional ingredient in durum wheat bread: rheological, sensory, and chemical characterization. CYTA J. Food. 19(1): 96-104.

Shedbalkar UU, Adki VS, Jadhav JP and Bapat VA, 2010. Opuntia and Other Cacti: Applications and Biotechnological Insights. Trop. Plant Biol. 3: 136-150.

Sundaram S, Radhakrishnan A, Kanniappan GV, Bhaskaran SK, Palanisamy CP and Kannappan P, 2015. Comparative Study on Antioxidant
Activity of Crude and Alkaloid Extracts of Hybanthus enneaspermus Linn) F. Mull. Anal. Chem. Lett. 5(5): 291-299.

Sznarkowska A, Kostecka A, Meller K and Bielawski $\mathrm{KP}$, 2017. Inhibition of cancer antioxidant defense by natural compounds. Oncotarget. 8(9): 15996.

Toure H, Bouatia M, Idrissi MO and Draoui M, 2015. Phytochemical screening and antioxidant activity of aqueous-ethanolic extracts of Opuntia ficus indica. J. Chem. Pharmaceut. Res. 7(7): 409-415.

Wang J, Green PS and Simpkins JW, 2001. Estradiol protects against ATP depletion, mitochondrial membrane potential decline and the generation of reactive oxygen species induced by 3nitroproprionic acid in SK-N-SH human neuroblastoma cells. J. Neurochem. 77(3): 804811.

Yubin JI, Miao Y, Bing W and Yao Z, 2014. The extraction, separation and purification of alkaloids in the natural medicine. J. Chem. Pharm. Res. 6(1): 338-345.

\section{Contribution of Authors}

Moussaoui B: Conceived idea, designed research methodology, executed the experiment, collected and analysed data, interpreted data, wrote manuscript.

Rahali A: Contributed in conceptualization of the study, experimental design and data interpretation, contributed in statistical analysis.

Hamed D: Literature review, helped in designing research methodology, data collection and data interpretation.

Guemou L: Literature review, planned the experiment and contributed in statistical analysis. Riazi A: Conceived idea, designed research methodology, edited and gave final approval of manuscript. 